\title{
RELATION BETWEEN THE MASS BALANCE OF WESTERN CANADIAN MOUNTAIN GLACIERS AND METEOROLOGICAL DATA
}

\author{
By ANNe Letréguilly*
}

(National Hydrology Research Institute, Saskatoon, Saskatchewan S7N 3H5, Canada)

ABSTRACT. The mass balance, summer balance, winter balance, and equilibrium-line altitude of three Canadian glaciers (Peyto, Place, and Sentinel Glaciers) are compared with the meteorological records of neighbouring stations for the period 1966-84. While Peyto Glacier's mass balance is almost entirely related to summer temperature, Sentinel Glacier's mass balance is mostly controlled by winter precipitation. Place Glacier is influenced by both elements. Statistical reconstructions are presented for the three glaciers, using the best regression equations with the meteorological records since 1938.

\section{INTRODUCTION}

In western Canada, the mass balances of three mountain glaciers have been measured annually since 1966. These glaciers have very different locations in the Rocky Mountains and Coast Mountains, and a number of meteorological stations can be found in their vicinity. This situation offers a good opportunity to study the relationships between glacier variations and climatic data, and specifically to evaluate the types of climatic information that can be provided by different glaciers. Such studies may be useful for the interpretation of net-balance data from ice cores.

Understanding how the climate influences glaciervolume changes is also useful for hydrologists, who are interested in the run-off from glaciers. Glacial run-off has the established characteristic of peaking in summer, when other sources are usually diminishing. Even if these seasonal variations are relatively well known, information on the volume change of glaciers from year to year is scarce. The longest records of mass balance in western Canada are just reaching 20 years. A good relationship with the most recent period of a long meteorological time series would make possible a reconstruction of mass-balance values from the past and thereby, through proxy data, lengthen these records. Such long records, covering a time span of a century, have been used to estimate the water loss from small mountain glaciers (Meier, 1984), and would seem to explain the difference between the observed rise of the ocean and the rise due to the thermal expansion.

Also, it has recently been suggested that valley glaciers may be sensisitive to the changes in tropospheric radiation balance caused by the presence of $\mathrm{CO}_{2}$ and other "green-house" gases in the atmosphere (Oerlemans, 1986).

The following study was made using the glaciological measurements (winter balance, summer balance, annual balance, and equilibrium-line altitude, or ELA) collected on three glaciers (Peyto Glacier in Alberta, Place and Sentinel Glaciers in British Columbia) and climatic data from meteorological stations within a distance of $200 \mathrm{~km}$ thereof.

*Present address: Alfred-Wegener-Institut für Polar- und Meeresforschung, 2850 Bremerhaven, Federal Republic of Germany.

\section{COMPUTATION METHOD}

The climatic data used are the monthly precipitation $\left(P_{\mathrm{i}}\right)$ and the monthly means of minimum $\left(t_{\mathrm{i}}\right)$ and maximum temperatures $\left(T_{\mathrm{i}}\right)$. The monthly values were used for two reasons: the data set could be conveniently obtained in that form from the Atmospheric Environment Service (1986[a], [b]) and this interval filters out the short-term fluctuations due to local and random processes such as thunderstorms.

The monthly series were then summed over periods of time ranging from 1 to 12 months in the hydrological year, from October to September:

$$
\begin{gathered}
P_{i j}=\sum_{t=i}^{j} P_{\mathrm{t}}, \\
T_{i j}=\sum_{t=i}^{j} T_{\mathrm{t}}, \\
t_{i j}=\sum_{t=i}^{j} t_{\mathrm{t}} .
\end{gathered}
$$

For example, $t_{7-8}$ or $t_{\text {July-August }}$ is the July mean of daily minima added to the August mean of daily minima.

The $P_{i j}$ series were computed for $i$ varying from 10 (October) to 9 (September) and the $T_{i j}$ and $t_{i j}$ series were computed for $i$ varying from 5 (May) to 9 (September). For each meteorological station, this kind of computation gave 66 precipitation series, ten minimum temperature series, and ten maximum temperature series. All those series (called $X$ series) were compared to the glaciological series: winter balance, summer balance, annual balance, and ELA ( $Y$ series). To evaluate the similarity or the differences between the $X$ and $Y$ series, a correlation coefficient was computed:

$$
R_{x y}=\frac{V_{x y}}{\left(V_{x x} V_{y y}\right)^{\frac{1}{2}}} .
$$

Where $V_{x x}, V_{y y}$, and $V_{x y}$ are the variances and crossvariance of $X$ and $Y$ :

$$
\begin{gathered}
V_{x x}=\sum_{t=1}^{n}\left(x_{\mathrm{t}}-\bar{x}\right)^{2} \quad V_{y y}=\sum_{t=1}^{n}\left(y_{\mathrm{t}}-\bar{y}\right)^{2} \\
V_{x y}=\sum_{t=1}^{n}\left(x_{\mathrm{t}}-\bar{x}\right)\left(y_{\mathrm{t}}-\bar{y}\right),
\end{gathered}
$$

$x_{\mathrm{t}}$ and $y_{\mathrm{t}}$ are elements of the $X$ and $Y$ series (values for year $t$ ). $x$ and $\bar{y}$ are the means of the $X$ and $Y$ series.

This correlation coefficient is useful in assessing the importance of one particular meteorological variable over the variations of the mass balance (or the other glaciological variables). However, more than one climatological variable 
may influence the mass balance. A multiple correlation coefficient $R_{\mathrm{m}}$ was also used to evaluate the combined effect of precipitation and temperature on the mass balance:

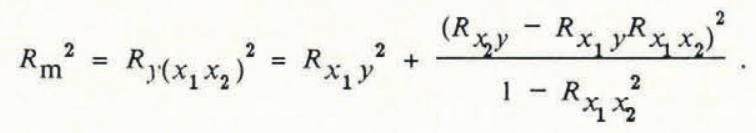

This multiple correlation coefficient (for two dependent variables) was only computed using the series shown in Tables II, IV, and V. This selection was done to reduce the calculation times.

With series 19 years long, a correlation coefficient is significant at the $5 \%$ level only when it is higher than 0.44 for simple linear regression, or 0.56 for bilinear regression (Chatfield, 1983).

To reconstruct the mass-balance series before the measurement period, a linear relationship with one or two climatological variables was taken:

$$
\begin{gathered}
\hat{y}=a_{0}+a_{1}\left(x_{1}-\bar{x}_{1}\right) \\
\hat{y}=a_{0}+a_{1}\left(x_{1}-\bar{x}_{1}\right)+a_{2}\left(x_{2}-\bar{x}_{2}\right),
\end{gathered}
$$

$\hat{y}$ is the estimated mass balance, $x_{1}$ and $x_{2}$ are meteorological variables having a good correlation or anti-correlation coefficient (as close as possible to 1 or -1 ) with the mass balance. $\bar{x}_{1}$ and $\bar{x}_{2}$ are the means of $X_{1}$ and $X_{2} . a_{1}, a_{2}$, and $a_{3}$ are coefficients computed using a least-squares method.

\section{PEYTO GLACIER}

Peyto Glacier is located in the Canadian Rocky
Mountains east of the Alberta-British Columbia border. It is situated about $100 \mathrm{~km}$ north-west of Banff. There are a large number of climatological stations in its vicinity (Fig. 1): Lake Louise, Banff, Jasper, Calgary, and Edmonton in Alberta, and Golden in British Columbia. Revelstoke was not used because the station was moved in 1969, without any simultaneous measurements at both sites. A station had also been in operation since 1965 near the front of the glacier, but only the data for 1967-78 and 1980-84 are available. The station was operated only in summer, usually from mid-May to mid-September, and occasionally October. The months used for the present study are June, July, and August.

The correlation coefficients, simple or multiple, between the Peyto Glacier variables and all the meteorological series (minimum temperature, maximum temperature, and precipitation) have been computed. Only the main results are shown in Table II. Most of the 1557 simple and about 1500 multiple correlation coefficients that were obtained for this glacier are not significant at the $5 \%$ level.

Table II shows an array of different and sometimes contradictory results. The most striking of these are:

1. The best correlations are obtained between Jasper's minimum summer temperatures and either the annual mass balance, or the ELA.

2. Annual balances correlate better with summer temperatures than do the summer balances.

3. Precipitation is either poorly or not at all correlated with the mass balance and ELA.

4. Data from the closest meteorological stations do not give the best correlation as the barely significant results from Peyto station show.

TABLE I. GLACIOLOGICAL MEASUREMENTS ON THE THREE GLACIERS STUDIED AND SIMPLE STATISTICAL DESCRIPTION OF THE SERIES

Year

Peyto Glacier

$\begin{array}{crrrr} & b_{\mathrm{w}} & b_{\mathrm{S}} & b_{\mathrm{a}} & E L A \\ 1966 & 124 & 109 & 15 & 2610 \\ 1967 & 206 & 205 & 1 & 2620 \\ 1968 & 163 & 128 & 35 & 2620 \\ 1969 & 143 & 183 & -40 & 2700 \\ 1970 & 107 & 277 & 170 & 2950 \\ 1971 & 131 & 172 & -41 & 2700 \\ 1972 & 167 & 192 & -25 & 2680 \\ 1973 & 172 & 129 & 43 & 2580 \\ 1974 & 162 & 138 & 24 & 2600 \\ 1975 & 115 & 172 & -57 & 2720 \\ 1976 & 166 & 102 & 64 & 2550 \\ 1977 & 89 & 110 & -21 & 2580 \\ 1978 & 111 & 216 & -105 & 2800 \\ 1979 & 125 & 206 & -81 & 2750 \\ 1980 & 79 & 137 & -105 & 2700 \\ 1981 & 103 & 215 & -112 & 2764 \\ 1982 & 124 & 181 & -56 & 2703 \\ 1983 & 87 & 126 & -39 & 2656 \\ 1984 & 121 & 178 & -58 & 2711 \\ & & & & \\ \text { Mean } & 184 & 238 & -54 & 2187 \\ \text { s.d. } & 41 & 46 & 72 & 154 \\ & & & & \end{array}$

Place Glacier

$\begin{array}{rrrr}b_{\mathrm{w}} & b_{\mathrm{S}} & b_{\mathrm{a}} & E L A \\ 202 & 191 & 11 & 2020 \\ 210 & 331 & -121 & 2370 \\ 232 & 245 & -13 & 2030 \\ 205 & 226 & -21 & 2090 \\ 143 & 294 & -151 & 2380 \\ 204 & 238 & -34 & 2050 \\ 176 & 210 & -34 & 2050 \\ 179 & 209 & -30 & 2185 \\ 277 & 221 & 56 & 2010 \\ 165 & 189 & -24 & 2080 \\ 243 & 155 & 84 & 1960 \\ 132 & 255 & -123 & 2250 \\ 173 & 216 & -43 & 2230 \\ 107 & 328 & -221 & >2500 \\ 150 & 242 & -92 & 2315 \\ 155 & 264 & -109 & 2310 \\ 201 & 276 & -75 & 2305 \\ 174 & 218 & -44 & 2285 \\ 172 & 206 & -34 & 2140 \\ & & & \\ 131 & 167 & -38 & 2684 \\ 34 & 46 & 60 & 94\end{array}$

Sentinel Glacier

\begin{tabular}{rrrr}
$b_{\mathrm{w}}$ & $b_{\mathrm{S}}$ & \multicolumn{1}{c}{$b_{\mathrm{a}}$} & $E L A$ \\
328 & 313 & 15 & 1820 \\
421 & 439 & -18 & 1875 \\
342 & 304 & 38 & 1720 \\
352 & 340 & 12 & 1800 \\
262 & 392 & -130 & 2080 \\
386 & 329 & 57 & 1795 \\
294 & 268 & 26 & 1825 \\
338 & 260 & 78 & 1750 \\
481 & 270 & 211 & 1600 \\
296 & 208 & 88 & 1790 \\
391 & 244 & 147 & 1670 \\
207 & 340 & -133 & 1995 \\
284 & 248 & 36 & 1830 \\
201 & 375 & -174 & 2060 \\
302 & 275 & 27 & 1830 \\
285 & 268 & 17 & 1865 \\
404 & 318 & 86 & 1775 \\
395 & 275 & 120 & 1690 \\
329 & 244 & 85 & 1780 \\
& & & \\
331 & 300 & 31 & 1818 \\
71 & 58 & 95 & 122
\end{tabular}

Correlation coefficients

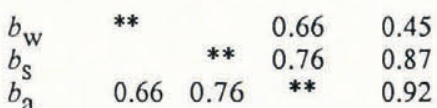

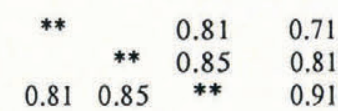

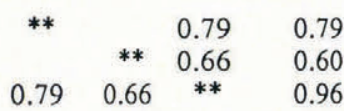

$b_{\mathrm{w}}$ Winter balance (cm of water).

$b_{\mathrm{S}} \quad$ Summer balance (cm of water).

$b_{\mathrm{a}}$ Annual mass balance (cm of water).

ELA Equilibrium-line altitude $(\mathrm{m})$.

s.d. Standard deviation. 
TABLE II. CORRELATION COEFFICIENTS OF THE METEOROLOGICAL DATA OF SEVEN STATIONS WITH THE ANNUAL MASS BALANCE OF PEYTO GLACIER FOR THE PERIOD 1966-84. BLANKS INDICATE A COEFFICIENT BELOW THE 5\% SIGNIFICANCE LEVEL. THE METEOROLOGICAL DATA ON PEYTO GLACIER ARE 12 YIAARS LONG (1967-78) AND THE

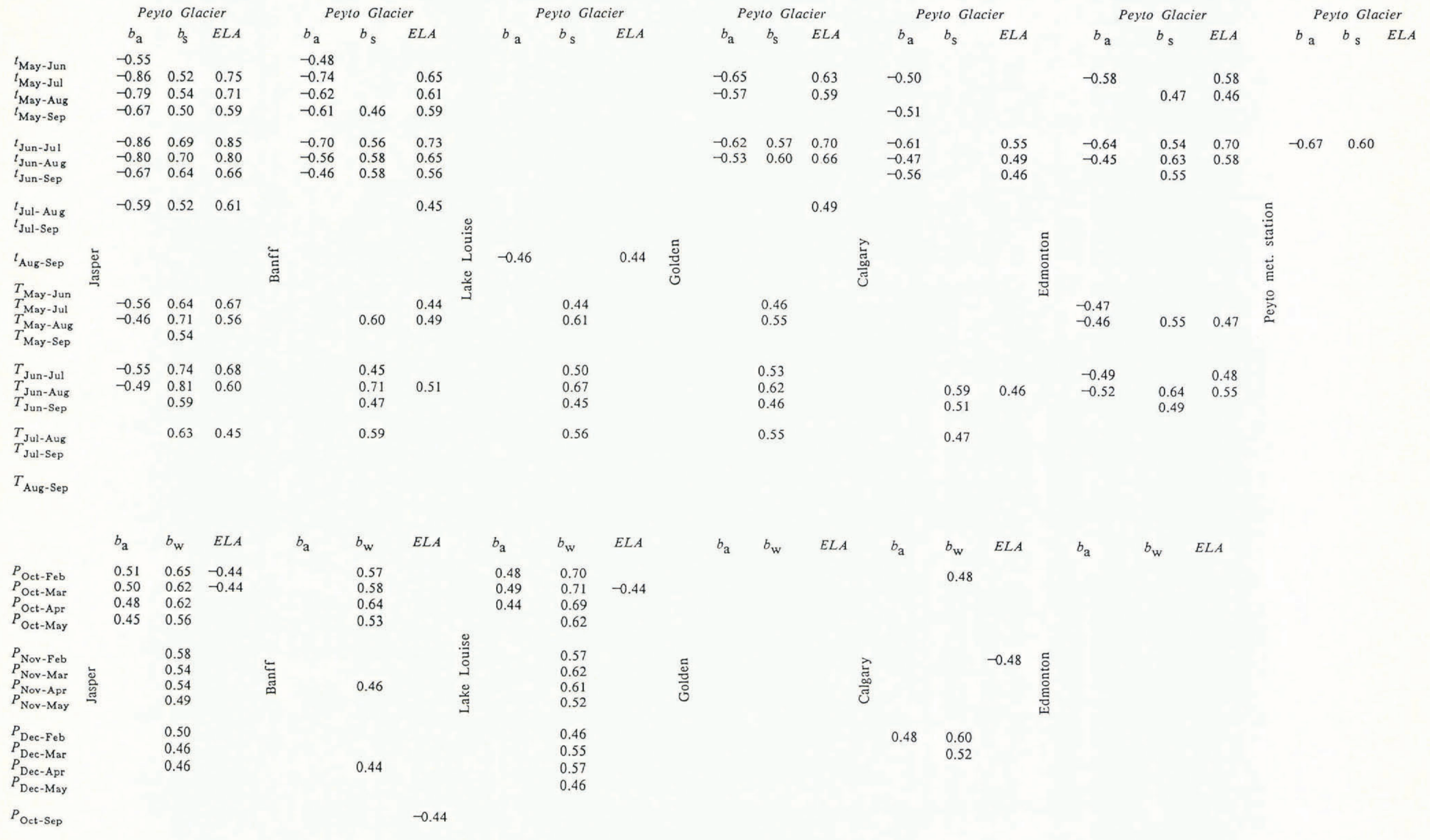




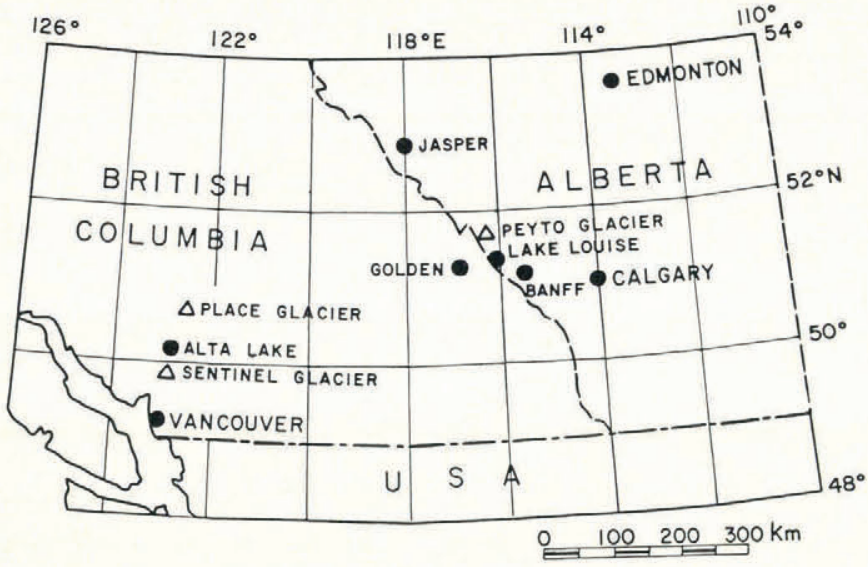

meteorological station $\triangle$ GLACIER

Fig. 1. Location of glaciers and meteorological stations used in this study.

\section{These points are now discussed:}

1. The fact that summer temperatures play an important part in the regime of a glacier has already been shown by other statistical studies (Young, 1977; Martin, 1978; Tangborn, 1980). However, the month of August usually accounts for some of the variance, which is apparently not the case here, although the temperature, as well as the runoff from the glacier, is still very high in this month. Also, the minimum temperature is better correlated with the mass balance than the maximum temperature (the mean always has coefficients between the minimum and the maximum). The explanation for this seems to be related to the variance in the daily temperature series. The variance of the maximum temperature is much higher than that of the night temperature for the summer months in Banff and Jasper (the standard deviation of the maximum temperature is almost twice that of the minimum temperatures). The night (minimum) temperatures would seem to be essentially filtered of the daily noise seen in the daily maximum of mean temperature.

2 and 3. The statistical method used can only associate time (or other) series with similar fluctuations. The regression equation thus obtained does not always give a realistic description of the series, in this case the mass balance; the precipitation is just as important in the accumulation process as the temperature is in the melting process. What the regression method points out, however, is that the interannual variations of precipitation have very little effect on the inter-annual variations of the mass balance; the controlling factor of these mass-balance variations is the temperature of June-July. Their deviation from the normal will affect the mass balance much more than a deviation in the precipitation. Indeed, Table I shows that the mass balance of Peyto and Place Glaciers is more related to the summer balance than the winter balance. Also, the summer balances have wider variations than the winter balances, as can be seen from Figure 2 or from the standard deviations.

Combining the best summer-balance estimation (Jasper minimum temperature of June-July) with the best winterbalance estimation (Lake Louise precipitation of OctoberMarch) was tried but the result is not as good as a direct correlation of the summer temperature with the mass balance.

4. It is quite unexpected that the best correlation using temperature data is not obtained with the closest station. In fact, the ranking of coefficients is almost the opposite of what might be expected: Jasper, $200 \mathrm{~km}$ away, gives the best correlation coefficient, followed by Banff, $100 \mathrm{~km}$ away, then Lake Louise, $40 \mathrm{~km}$ away, and finally Peyto station, only a few hundred meters from the glacier. Golden, Calgary, and Edmonton records also show little relation to the Peyto Glacier data. One of the explanations for this has to be sought in the reliability of the records.

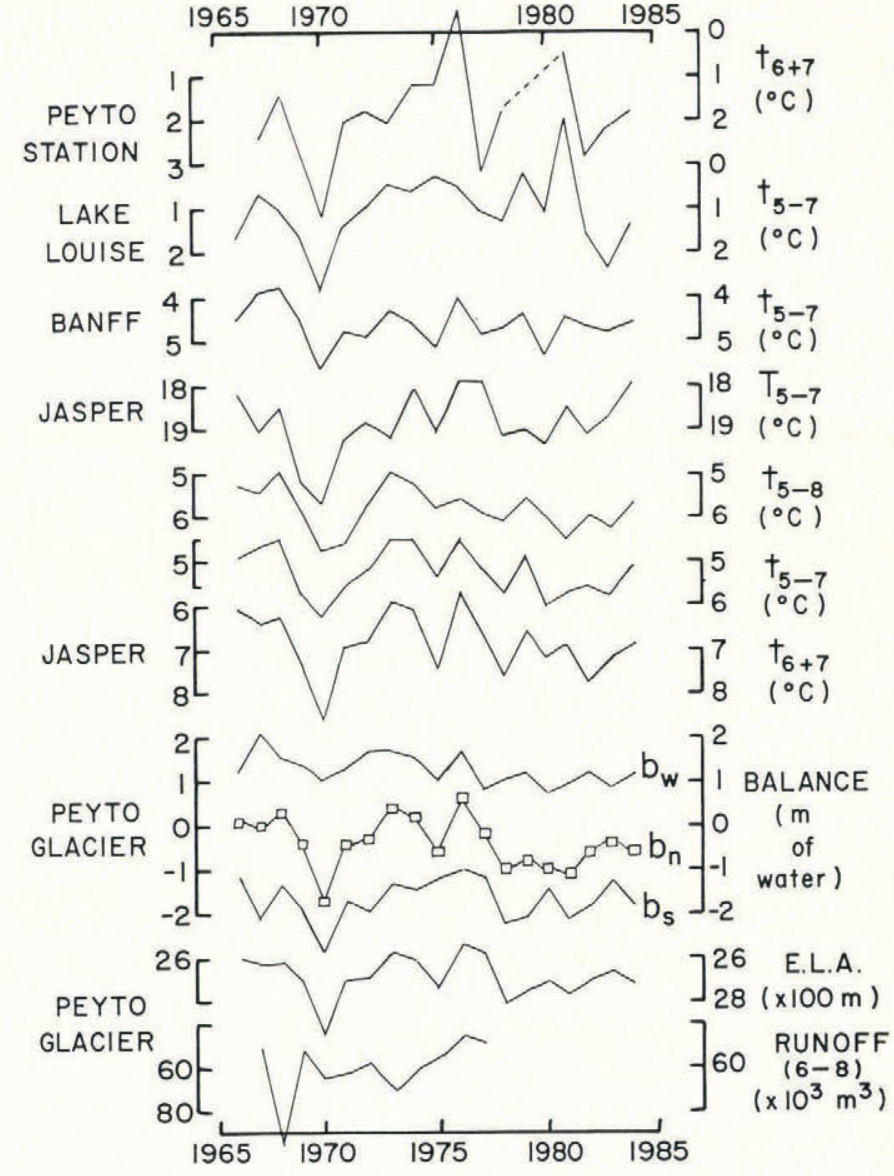

Fig. 2. Glaciological and hydrological measurements on Peyto Glacier (annual, winter and summer balance, equilibrium-line altitude, and run-off from glacier stream) and temperature series of neighbouring meteorological stations of the Canadian Rockies. The scale of the temperature is reversed (negative values up) to facilitate the comparison with Peyto Glacier mass balance (drawn with $a \mathrm{D}$ ), since a positive mass balance corresponds to a low summer temperature. The most interesting temperature series have been plotted (from Banff, Jasper, Lake Louise, and Peyto station, near the glacier). $t_{5 \rightarrow 7}$ stands for the mean of the monthly minimum temperature of May, June, and July. $T_{5 \rightarrow 7}$ is the maximum temperature averaged over the same period of time, and $P_{5 \rightarrow 7}$ is the cumulative precipitation of May, June, and July. $b_{w}$ is the winter balance, $b_{a}$ the annual balance, and $b_{s}$ the summer balance.

For Lake Louise, nine of the monthly values are "missing" or "estimated" for the summer (May $\rightarrow$ August) minimum and maximum temperature, and six for the winter (October $\rightarrow$ May) for the period 1966-84. Furthermore, the weather station is located only $30 \mathrm{~m}$ from the railway line, opposite the railway station. On this railway line freight trains, sometimes $1 \mathrm{~km}$ long, run every half hour. These conditions contravene the standards for conducting meteorological measurements. In addition, the weather station has had three different locations since 1970. There are no records that any corresponding adjustments were made to the data. Peyto weather station does not seem to have a fully reliable record either, particularly after 1975. Also, the very proximity to the glacier could be the reason for additional noise; on days of down-glacier wind, the cold boundary air layer that normally covers the glacier can extend to the station, which would lower the temperature. On calm days, the station temperature would be higher than on the glacier. The record therefore might reflect the wind conditions as well as the temperature. On the other hand, Jasper does not have a single missing or estimated value in the whole record of precipitation and temperature since 1941. It is also a first-order weather station with a fulltime professional observer. The correlation coefficients between mass balance and meteorological elements seem to 
be able to indicate the precision, or at least the appropriateness, of the meteorological records.

Correlation coefficients between the meteorological variables and the ELA are very similar to, or sometimes even higher than, those of the mass balance. The ELA seems to be as reliable an indicator of the Peyto Glacier regime variations as is the mass balance. This is in accordance with the results of Young (1977) over a shorter period.

If only the series up to 1975 or 1980 are used, the correlation with the temperature increases (Table III). Using the precipitation data instead of the temperature does not make any significant difference to the $R$ values. This effect is particularly noticeable using the Lake Louise data, which show a significant correlation coefficient for the temperature only for the period 1966-80. This can be seen on Figure 2 , where the plotted temperature series have shapes closer to the mass-balance curve for the pre-1980 period. Since it is unlikely that all the meteorological stations produced defective data at the same time, another reason for the divergence must come from the mass-balance data. During 1966-75 (I.H.D.), the Canadian mass-balance program was operated as a priority. Since then, less attention has been given to it. Peyto Glacier was not visited as of ten as before and some of the poles were lost. This has resulted in a progressive loss of accuracy during recent years, particularly after 1980. This loss of accuracy may be the cause of the reduction in correlation coefficient.

\section{PLACE AND SENTINEL GLACIERS}

These two glaciers are situated in the Coast Mountains about 80 and $140 \mathrm{~km}$, respectively, north of Vancouver (Fig. 1). Mass-balance measurements were initiated in 1966 for the I.H.D. and they include some meteorological data (Mokievsky-Zubok and others, unpublished). These glaciers are not, however, surrounded by many meteorological stations with continuous records. Vancouver and Alta Lake meteorological stations were the only two considered. The mass balance of the glaciers is plotted in Figure 3, as well as some of the meteorological variables from the two stations.

The glaciological data were correlated with the meteorological variables using the same method as for Peyto Glacier. The results are shown in Tables IV and V. Unlike

TABLE III. CORRELATION COEFFICIENTS BETWEEN PEYTO GLACIER GLACIOLOGICAL DATA AND CLIMATOLOGICAL DATA FROM THREE STATIONS FOR DIFFERENT PERIODS OF TIME

$$
\begin{array}{cccc}
\begin{array}{c}
1966-84 \\
\left(R_{\min }=0.44\right)
\end{array} & \begin{array}{c}
1966-80 \\
\left(R_{\min }=0.51\right)
\end{array} & \begin{array}{c}
1966-75 \\
\left(R_{\min }=0.63\right)
\end{array} \\
b_{\mathrm{a}} \quad E L A & b_{\mathrm{a}} \quad E L A & b_{\mathrm{a}} \quad E L A
\end{array}
$$

Jasper

$\begin{array}{lrrrrrr}t_{\text {Jun }+ \text { Jul }} & -0.85 & 0.85 & -0.92 & 0.91 & -0.98 & 0.97 \\ P_{\text {Oct } \rightarrow \text { Mar }} & 0.50 & & 0.54 & & & \end{array}$

Banff

$\begin{array}{lllllll}t_{\mathrm{Jun}+\mathrm{Jul}} \quad-0.70 & 0.73 & -0.83 & 0.82 & -0.85 & 0.85\end{array}$

$P_{\text {Oct } \rightarrow \text { Mar }}$

Lake Louise

$\begin{array}{llllll}t_{\text {Jun }+\mathrm{Jul}} & & -0.58 & 0.72 & -0.75 & 0.80 \\ P_{\text {Oct } \rightarrow \text { Mar }} & 0.49 & 0.52 & & & \end{array}$

$R_{\min }$ is the minimum correlation coefficient significant at the $95 \%$ level.

ELA is the equilibrium-line altitude.

$b_{\mathrm{a}}$ is the annual mass balance.
Peyto Glacier, the winter precipitation, summed over at least 3 months is quite highly correlated with the mass balance. The data-summing interval that gives the best correlation is not always the same, but it always includes the months of heavy precipitation: November, December, and January. The other months, although not insignificant, are not as decisive in influencing the variations of the mass balance. Indeed, Figure 3 shows that the plot of the average precipitation from November to March resembles, very closely, the average precipitation from October to May.

For Place Glacier, temperature series from Vancouver show better correlations with the glaciological series than the temperature series from Alta Lake, while the precipitation series from Alta Lake are better correlated with the glaciological series than those of Vancouver. For Sentinel Glacier, the correlation coefficients do not show any significant difference whether climatic series from Alta Lake or Vancouver are used. Alta Lake is a mountain station, closer to the two glaciers than Vancouver, and therefore its records should correlate better with either set of glaciological data. The station was moved in 1976 and the record shows missing or estimated values; therefore the reliability of this data set must be questioned.

When precipitation is used in combination with temperature, Vancouver station gives a better correlation coefficient (Tables IV and V). Although the two glaciers are located in the same mountain range, the relative influence of the winter precipitation and summer temperature on the mass-balance variations is evidently not the same; on Sentinel Glacier, the major controlling factor is the winter precipitation, while on Place Glacier winter precipitation and summer temperature have an equal share. The features can also be observed in Table I, which shows the correlation

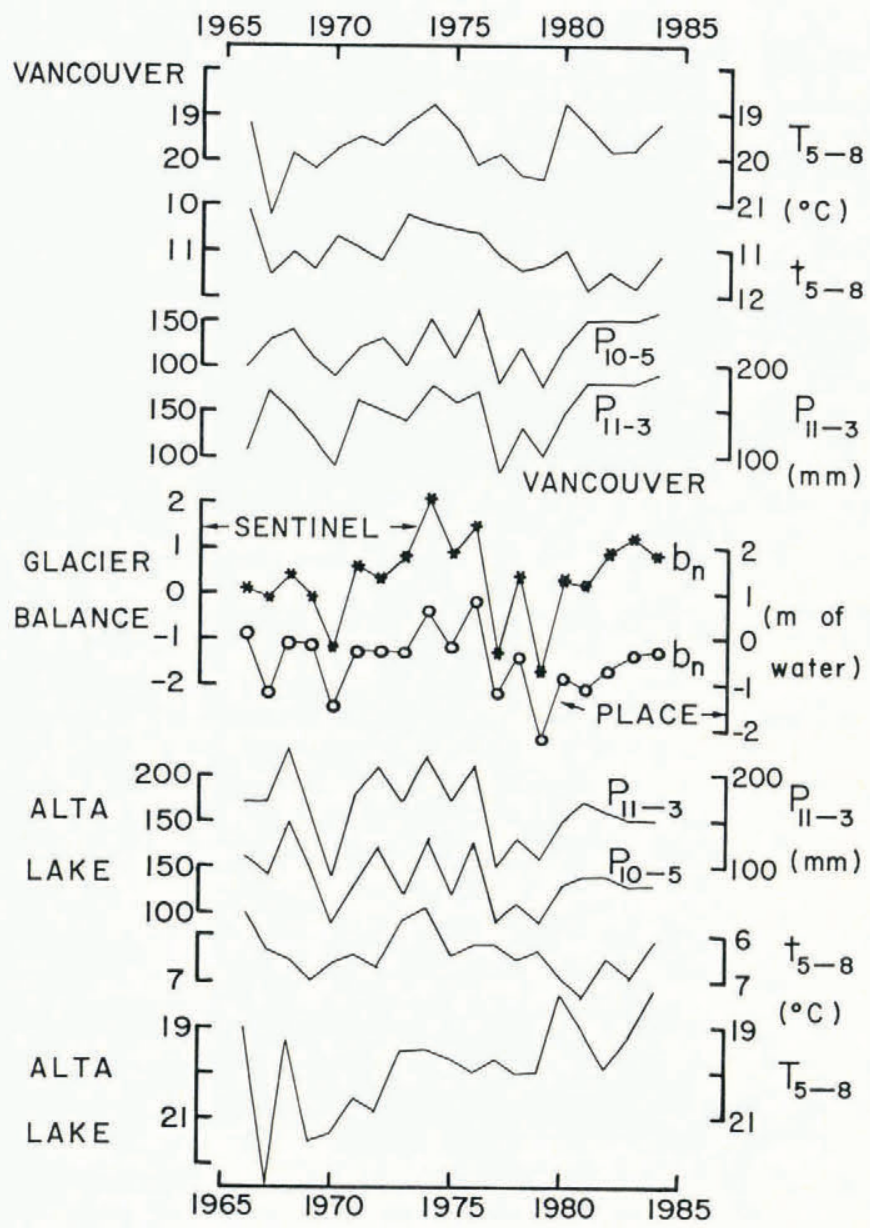

Fig. 3. Mass balance of Place Glacier (O) and Sentinel Glacier (*), and meteorological series from Vancouver and Alta Lake for the period 1966-84. $t_{5 \rightarrow 7}$ stands for the mean of the monthly minimum temperature of May, June, and July. $T_{5 \rightarrow 7}$ is the maximum temperature averaged over the same period of time, and $P_{5 \rightarrow 7}$ is the cumulative precipitation of May, June, and July. $b_{a}$ is the annual balance. 
TABLE IV. CORRELATION COEFFICIENTS BETWEEN PLACE GLACIER GLACIOLOGICAL DATA AND VANCOUVER AND ALTA LAKE METEOROLOGICAL VARIABLES FOR THE PERIOD 1966-84 (SUMMARY OF THE MOST SIGNIFICANT RESULTS). BLANKS MEAN THE VALUE IS BELOW THE 5\% SIGNIFICANCE LEVEL. $t_{\text {Jul-Aug }}, t_{\text {Jul-Sep }}, t_{\text {Aug-Sep }}$ ARE OMITTED BECAUSE THEY ${ }^{t}{ }_{\text {Jul-Aug }},{ }^{\text {Jul-Sep }}$ SHOW ${ }^{\text {Aug-Sep }}$ SIGNIFICANT RESULT

\begin{tabular}{|c|c|c|c|c|}
\hline & & $b_{\mathrm{a}}$ & $b_{\mathrm{S}}$ & $E L A$ \\
\hline May-Jun & & & & 0.45 \\
\hline$t_{\text {May-Jul }}$ & & & & 0.51 \\
\hline$t_{\text {May-Aug }}$ & & -0.46 & 0.47 & 0.52 \\
\hline$t_{\text {May-Sep }}$ & & & 0.48 & 0.53 \\
\hline$t_{\text {Jun-Jul }}$ & & & & 0.44 \\
\hline$t_{\text {Jun-Aug }}$ & & & 0.48 & 0.49 \\
\hline$t_{\text {Jun-Sep }}$ & & & 0.49 & 0.50 \\
\hline$T_{\text {May-Jun }}$ & & & 0.45 & \\
\hline$T_{\text {May-Jul }}$ & בั & & 0.45 & \\
\hline$T_{\text {May-Aug }}$ & $\stackrel{\text { ला }}{>}$ & -0.58 & 0.68 & 0.52 \\
\hline$T_{\text {May-Sep }}$ & & -0.49 & 0.70 & 0.51 \\
\hline$T_{\text {Jun-Jul }}$ & & -0.59 & 0.50 & \\
\hline$T_{\text {Jun-Aug }}$ & & -0.46 & 0.71 & 0.51 \\
\hline$T_{\text {Jun-Sep }}$ & & -0.52 & 0.70 & 0.48 \\
\hline$T_{\text {Jul-Aug }}$ & & & 0.58 & \\
\hline$T_{\text {Jul-Sen }}$ & & & 0.56 & \\
\hline$T_{\text {Aug-Sep }}$ & & & 0.48 & \\
\hline
\end{tabular}

\begin{tabular}{|c|c|c|c|c|c|c|c|}
\hline & & $b_{\mathrm{a}}$ & $b_{\mathrm{w}}$ & $E L A$ & $b_{\mathrm{a}}$ & $b_{\mathrm{w}}$ & $E L A$ \\
\hline$P_{\text {Oct-Feb }}$ & & 0.50 & 0.61 & & 0.75 & 0.85 & -0.68 \\
\hline$P_{\text {Oct-Mar }}$ & & 0.56 & 0.66 & & 0.75 & 0.86 & -0.72 \\
\hline$P_{\text {Oct-Apr }}$ & & 0.51 & 0.60 & & 0.73 & 0.84 & -0.72 \\
\hline$P_{\text {Oct-May }}$ & & 0.53 & 0.61 & & 0.74 & 0.84 & -0.72 \\
\hline$P_{\text {Nov-Feb }}$ & & & & & 0.74 & 0.79 & -0.70 \\
\hline$P_{\text {Nov-Mar }}$ & & 0.44 & 0.49 & & 0.75 & 0.80 & -0.75 \\
\hline$P_{\text {Nov-Apr }}$ & $\stackrel{\overrightarrow{0}}{3}$ & & & 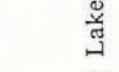 & 0.72 & 0.79 & -0.74 \\
\hline$P_{\text {Nov-May }}$ & 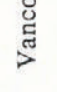 & & 0.44 & $\frac{\pi}{<}$ & 0.72 & 0.78 & -0.74 \\
\hline$P_{\text {Dec-Feb }}$ & & & 0.48 & & 0.57 & 0.67 & -0.54 \\
\hline$P_{\text {Dec-Mar }}$ & & 0.46 & 0.57 & & 0.60 & 0.70 & -0.62 \\
\hline$P_{\mathrm{Dec}-\mathrm{Apr}}$ & & & 0.50 & & 0.57 & 0.69 & -0.61 \\
\hline$P_{\text {Dec-May }}$ & & 0.45 & 0.53 & & 0.58 & 0.69 & -0.62 \\
\hline$P_{\text {Oct-Sep }}$ & & 0.51 & 0.53 & & 0.68 & 0.76 & -0.68 \\
\hline
\end{tabular}

Best combination of two variables explaining $b_{\mathrm{a}}$ (multiple $R): \quad 0.82$ for $P_{10 \rightarrow 5}(28 \%)$ and $t_{5 \rightarrow 8}(39 \%)$ for Vancouver station.
TABLE V. CORRELATION COEFFICIENTS BETWEEN SENTINEL GLACIER GLACIOLOGICAL DATA AND VANCOUVER AND ALTA LAKE METEOROLOGICAL VARIABLES FOR THE PERIOD 1966-84 (SUMMARY OF THE MOST SIGNIFICANT RESULTS). BLANKS MEAN THE VALUE IS BELOW THE 5\% SIGNIFICANCE LEVEL. MINIMUM TEMPERATURES ARE OMITTED BECAUSE THEY SHOW NO SIGNIFICANT RESULT



Best combination of two variables explaining $b_{a}$ (multiple $R)$ : 0.89 for $P_{10 \rightarrow 5}(60 \%)$ and $t_{5 \rightarrow 8}(17 \%)$ for Vancouver.

coefficients between the winter, summer, and annual balances, and their respective standard deviations; the winter balance $\left(b_{\mathrm{w}}\right)$ of Sentinel Glacier has a higher standard deviation than the summer balance, and $b_{\mathrm{w}}$ is also more closely correlated to the annual mass balance, indicating again that the winter accumulation is the dominant factor in the mass balance.

As with Peyto Glacier, the ELA and the mass balance of both glaciers have similar correlation coefficients with the meteorological variables. The ELA is thus a good indicator of the variation of mass balance of Place and Sentinel Glaciers. 
With about $70 \%$ of the variance explained, a reconstruction of mass balance can be attempted, using the regression equation and the meteorological data. For Peyto Glacier, it is:

$$
\hat{b}=-32 t_{5 \rightarrow 7}+457
$$

where $\hat{b}$ is the generated mass balance (cm of water) and $t_{5 \rightarrow 7}$ is the sum of the mean monthly minimum temperature for May, June, and July in Jasper.

The cumulative generated mass balance for the period 1938-84 is shown in Figure 4 , as well as the measured values for 1966-84. This representation was chosen, rather than simply the mass balance, because it shows directly the evolution of the ice reservoir.

For the period 1966-84, the two curves are quite close. Before 1966, however, the data available to check the validity of the reconstructed curve are scarce. Terminal position measurements were made on Peyto Glacier from 1933 to 1965 , and their correlation with the reconstructed curve is good at lags of 9,3 , and 11 years. The glacier has a weak response time at 3 years and a stronger one at about 10 years. The sharp increase in mass balance that reached its maximum around 1955 would thus be expected to have started influencing the glacier terminus in 1965 . Unfortunately, at that time the front measurements were discontinued until 1984, so that method cannot be used to test the reconstruction. Furthermore, the ice front at that time occupied a much narrower gorge than today. This change in the valley topography might have caused a variation in the length of the glacier independent of the climate.

This reconstructed curve is compared with another reconstruction based on the Banff station data:

$$
\hat{B}=-31 t_{5 \rightarrow 7}+401 \text {. }
$$

The cumulative values are also plotted in Figure 4, where it can be seen that the agreement with the measurements is not as good as with the Jasper data (only $50 \%$ of the variance is explained). Peyto Glacier shows a stationary period during 1970-76 which is followed closely by the Jasper reconstruction, but the Banff reconstruction just declines quite regularly since 1965, following the general

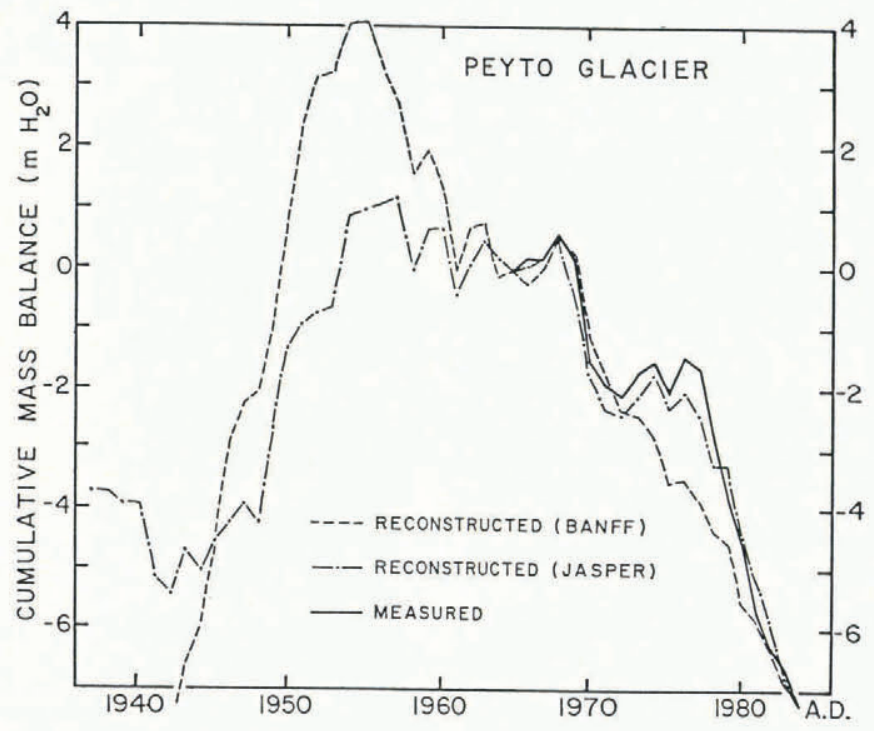

Fig. 4. Cumulative mass balance of Peyto Glacier (1966-84) and reconstructions obtained with Jasper and Banff summer temperature $(1938-84)$. The regression equations used are:

$$
\begin{aligned}
& \text { Jasper: } b_{a}=-32 t_{5 \rightarrow 7}+457 \\
& \text { Banff: } b_{a}=-31 t_{5 \rightarrow 7}+401
\end{aligned}
$$

where $t_{5 \rightarrow 7}$ is the sum of the mean monthly minimum temperature of May. June, and July. trend but not the details. The gap becomes wider for the pre-measurement period, but both curves indicate a growth of the glacier from 1942 to 1954. Before 1954, the two curves deviate widely and cannot be trusted.

It is noteworthy that the maximum of those two curves should occur around 1955 at a time when many other glaciers were at their lowest volume. In the European Alps, glaciers were decreasing rapidly during the 1940-50 decade, but have been slowly gaining some mass since then.

\section{SENTINEL AND PLACE GLACIERS RECONSTRUCTIONS}

Reconstructions were also made for Sentinel and Place Glaciers, using Vancouver airport data:

$$
\text { Sentinel Glacier: } \hat{b}=21 t_{5 \rightarrow 8}+0.39 P_{10 \rightarrow 5}+551 \text {. }
$$

The precipitation term accounts for $60 \%$ of the variance and the temperature term $17 \%$.

$$
\text { Place Glacier: } \hat{b}=23 t_{5 \rightarrow 8}+0.23 P_{10 \rightarrow 5}+742 \text {. }
$$

$28 \%$ of this variance is explained by the precipitation and $39 \%$ by the temperature.

The reconstructions are plotted in Figures 5 and 6 for 1938 to 1985, together with the measured data for 1966 to 1984. Although meteorological series were available for Vancouver (City) before 1938, the reconstruction was terminated there on the basis of previous reconstructions.

The three reconstructed curves for Peyto, Place, and Sentinel Glaciers differ widely: from 1938 the Peyto Glacier curve increases rapidly before attaining a stable period and then decreasing. The Place Glacier curve is dominated by an overall decreasing trend, while the Sentinel Glacier curve shows a succession of cycles of $10-15$ years on an increasing trend. When the general trends are removed from the curves in Figures 4, 5, and 6 , some similarities appear in

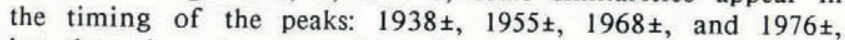
but they do not seem to be related to any known cycles.

\section{SUMMARY AND CONCLUSIONS}

The choice of the glaciers in this study was largely influenced by the length of the available mass-balance records. The three glaciers studied represent an interesting selection; Peyto Glacier, in the eastern Rockies, has variations in mass balance mostly controlled by summer temperatures, Sentinel Glacier shows variations which tend

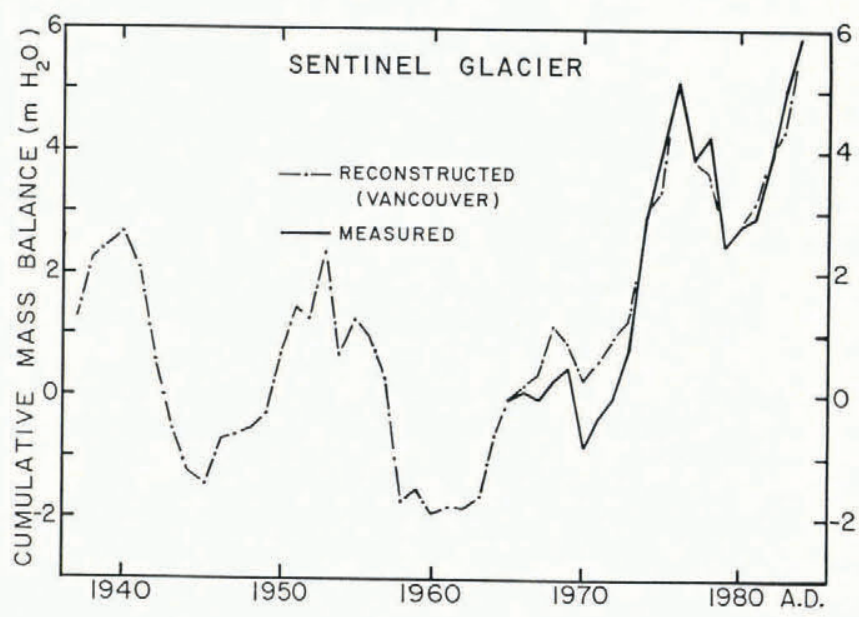

Fig. 5. Cumulative mass balance of Sentinel Glacier (1966-84) and reconstruction obtained with Vancouver meteorological data, using the regression equation:

$$
b_{a}=-0.4 P_{10 \rightarrow 5}-21 t_{5 \rightarrow 8}+551
$$

where $P_{10 \rightarrow 5}$ is the cumulative monthly precipitation from October to May, and $t_{5 \rightarrow 8}$ is the cumulative mean monthly minimum from May to August. 


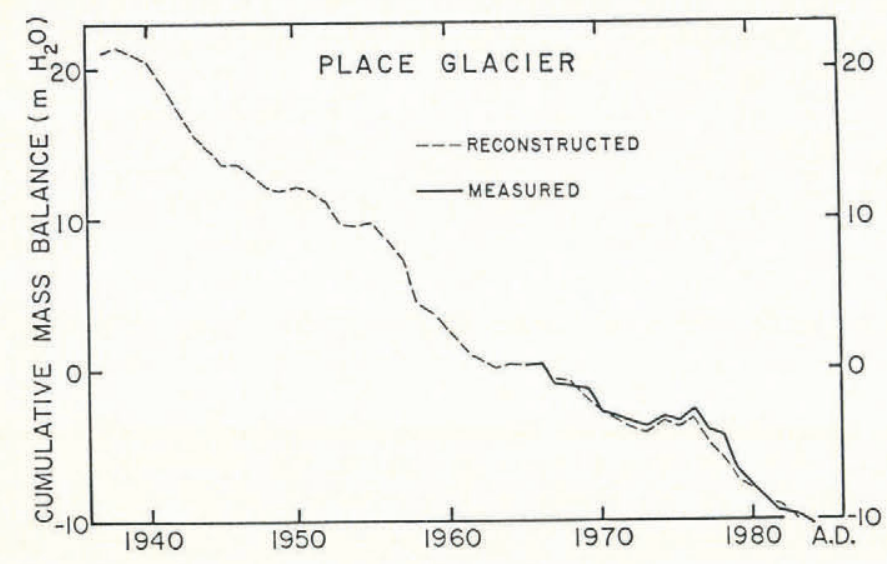

Fig. 6. Cumulative mass balance of Place Glacier (1966-84) and reconstruction obtained with Vancouver meteorological data using the regression equation:

$$
b_{a}=-0.2 P_{10 \rightarrow 5}-23 t_{5 \rightarrow 8}+742
$$

where $P_{10 \rightarrow 5}$ is the cumulative monthly precipitation from October to May, and $t_{5 \rightarrow 8}$ is the cumulative mean monthly minimum from May to August.

to be highly dependent on precipitation (as would be expected with the maritime climate), while Place Glacier is controlled by both factors.

With Peyto Glacier it was unexpected that the meteorological variables from the closest station did not have the best relation to the mass-balance fluctuations. One explanation for this is the lack of reliability in the measurements. The example of Lake Louise shows that a correlation may easily be hidden by just a few years of less accurate meteorological data. Also, the glaciological measurements may not be of uniform quality. For instance, when reliable meteorological data are used (Jasper or Banff), it can be seen that the last 4 years of mass-balance data cause a significant drop in the correlation.

It should also be realized that a length of series of only 19 years constrains the application of statistical methods, considering the uncertainties associated with the glaciological measurements. No reliable relationships can be assumed until the record approaches 50 years in length. For this reason, it is important to continue the glacier measurements. In the meantime, decade-to-decade studies such as this one can only give general indications. Until a reliable physical model can be built, however, an empirical statistical approach is still the most practical.
Continuing measurements of mass balance and glacier length could also be valuable in assessing the effects of green-house gases in the atmosphere.

\section{ACKNOWLEDGEMENTS}

This research was carried out while the author was a Visiting Fellow with the National Hydrology Research Institute in Calgary, Canada. The work was done under the supervision of $\mathrm{Dr}$ G. Holdsworth, to whom I am grateful. I wish to thank the Director of the Arctic Institute of North America, University of Calgary, for providing facilities during the last part of my tenure when the Institute moved to Saskatoon.

I am also grateful to S. Ommaney, O. MokeivskyZubok (N.H.R.I), and B. Goodison (Atmospheric Environment Service) for their comments. The paper is published with the approval of the Director, National Hydrology Research Institute, Saskatoon.

\section{REFERENCES}

Atmospheric Environment Service. 1986[a]. Monthly summaries of meteorological data in Alberta. Edmonton, Atmospheric Environment Service.

Atmospheric Environment Service. 1986[b]. Monthly summaries of meteorological data in British Columbia. Vancouver, Atmospheric Environment Service.

Martin, S. 1978. Analyse et reconstitution de la série des bilans annuels du Glacier de Sarennes, sa relation avec les fluctuations du niveau de trois glaciers du Massif du Mont-Blanc (Bossons, Argentiére, Mer de Glace). Zeitschrift für Gletcherkunde und Glazialgeologie, 13(1/2), 1977, 127-53.

Meier, M.F. 1984. Contribution of small glaciers to global sea level. Science, 226(4681), 1418-21.

Mokievsky-Zubok, O., Ommanney, C.S.L., and Power, J. Unpublished. N.H.R.I. glacier mass balance 1964-1984 (Cordillera and Arctic). Ottawa, Environment Canada. National Hydrology Research Centre. Surface Water Division. Glacier Section. (Internal Report.)

Oerlemans, J. 1986. Glaciers as indicators of a carbon dioxide warming. Nature, 320(6063), 607-09.

Tangborn, W. 1980. Two models for estimating climate-glacier relationships in the North Cascades, Washington, U.S.A. Journal of Glaciology, 25(91), 3-21.

Young, G.J. 1978. Relations between mass-balance and meteorological variables on Peyto Glacier, Alberta, 1967/74. Zeitschrift für Gletcherkunde und Glazialgeologie, 13(1/2), 1977, 111-25. 